This item was submitted to Loughborough's Research Repository by the author.

Items in Figshare are protected by copyright, with all rights reserved, unless otherwise indicated.

\title{
Probing deeper into the risks of slips, trips and falls for an ageing rail passenger population: applying a systems approach
}

\section{PLEASE CITE THE PUBLISHED VERSION}

http://dx.doi.org/10.1049/iet-its.2015.0047

\section{PUBLISHER}

(C) The Institution of Engineering and Technology

\section{VERSION}

AM (Accepted Manuscript)

\section{PUBLISHER STATEMENT}

This work is made available according to the conditions of the Creative Commons Attribution-NonCommercialNoDerivatives 4.0 International (CC BY-NC-ND 4.0) licence. Full details of this licence are available at: https://creativecommons.org/licenses/by-nc-nd/4.0/

\section{LICENCE}

CC BY-NC-ND 4.0

\section{REPOSITORY RECORD}

Waterson, Patrick, Victoria L. Kendrick, Roger Haslam, Thomas Jun, and Brendan Ryan. 2019. "Probing Deeper into the Risks of Slips, Trips and Falls for an Ageing Rail Passenger Population: Applying a Systems Approach". figshare. https://hdl.handle.net/2134/20240. 

Population: Applying a Systems Approach

\author{
P.E. Waterson ${ }^{1 *}$, V.L. Kendrick ${ }^{1}$, B. Ryan ${ }^{2}$, G.T. Jun $^{1}$ and R.A. Haslam ${ }^{1}$ \\ ${ }^{1}$ Human Factors and Complex Systems Group, Loughborough Design School, Loughborough University, \\ Loughborough, LE11 3TU, UK. \\ ${ }^{2}$ Human Factors Research Group, Department of Mechanical, Materials and Manufacturing Engineering, \\ Nottingham University, Nottingham, NG7 2RD, UK. \\ *p.waterson@lboro.ac.uk
}

\begin{abstract}
In this paper we report the findings from a study of the contributory factors leading to Slips, Trips and Falls (STF's) amongst elderly passengers at train stations. Our research also attempted to understand how these factors were likely to change in the future over the medium to long-term (the period 2035-2050). Our data draws on: stakeholder interviews with rail personnel and elderly passengers; a set of station observations carried out across the UK; and, a survey of the views of station managers. The findings point to a set of 22 contributory factors covering aspects of organisational, station environment and passenger (individual) influence on STF's. Amongst the factors which most concern station managers at the present and over the next few decades are: rushing behaviour on train platforms; the consumption of alcohol by passengers; aspects of station design (e.g., flooring); and, training for station staff as regard the risks of STF's. We summarise our findings in the form of a systems model which highlights priorities with regard to STF's in terms of all of the stakeholders taking part in the study. A final section discusses a set of issues which might form the basis for a future agenda for research and practice in this area.
\end{abstract}

\title{
1. Introduction
}

According to the 2012/13 UK Rail Standards and Safety Board Performance Report, the rate of harm per journey amongst passengers aged over 70 is five times higher than the average [1]. The majority of this harm occurs at stations and involves slips, trips and falls (66\%) and accidents involving stairs and escalators. By 2050 the proportion of the UK population over 75 is expected to rise to 9 million (12\% of the total population) and significant increases in the number of passengers traveling by rail are similarly forecasted over this time period. An ageing population is also likely to be less mobile [3] and in need of more support at stations (e.g., improved access for wheelchairs, rest areas). Future operational changes to the railway system as whole are likely to bring about the need to consider additional factors as they relate to an ageing passenger population (e.g., increased capacity leading to overcrowding; changes to ticketing and information provision; reduced dwell time of trains at stations [2]). These statistics and forecasts add up to a pressing need to manage risk and threats to safety for passengers which are brought about by increasing life expectancy and changes to the rail network. In particular, there is a need to ensure that the risk models used in rail are capable of addressing and taking these types of future requirements into 
account. These models also need to be enhanced and adapted in order to cover the changing demographics and other characteristics of passengers in the future.

\subsection{Previous research on factors contributing to rail passenger slips, trips and falls (STF's)}

Up to $30 \%$ of UK adults over the age of 65 experience a fall each year, with one in five falls requiring medical attention [4]. A fall can be described as "an unintentional change in body position resulting in contact with the ground or with another lower level” [4]. A recent review of the literature concerning falls epidemiology, injury mechanisms, and falls-prevention strategies demonstrated that falls result in significant morbidity and mortality among the elderly [5]. Moreover, with increasing age adults may fall more often, due to a number of contributory factors including problems with balance, poor vision, and dementia [4]. A number of models have been proposed in order to summarise some of the main factors which contribute to the incidence of STF's amongst the elderly. Figure 1 for example shows an example of a systems model (adapted from [6]) which explains the role played by individual behaviour, person, organisational and environmental factors which contributes to passenger STFs. STF's are likely to happen as a combined result of factors surrounding the individual (e.g., knowledge, skills, motivation), the person (e.g., health and mobility), the organisation (e.g., safety culture, education, training), and the environment (e.g., weather, floor surface, warnings).

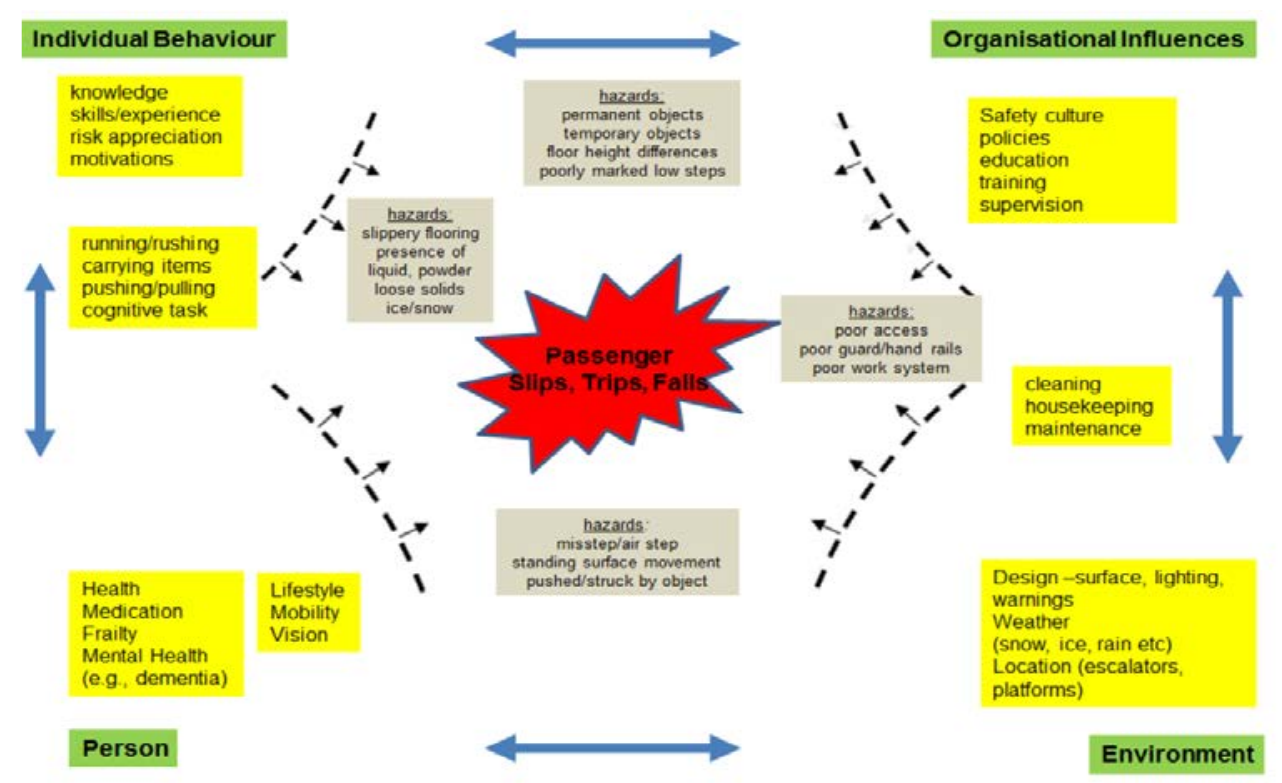

Fig. 1. Systems Model of Passenger-related Slips, Trips and Falls (adapted from [6]). 


\subsection{Research aims and the systems approach}

The overall aim of the research was to develop a better understanding of current factors which contribute towards the incidence of STF's amongst older passengers (defined as being over 65 years of age) at UK train stations. Part of this involved further developing and refining the model outlined in Figure 1. A second aim of the research was to assess the degree to which contributory factors leading to STF's are likely to change in the future (in this case over the period 2035-2050). In order to address this second aim, a range of stakeholders (including station managers and older passengers) were asked to rate which of the factors was likely to be a priority in the future, particularly in terms of the need for new interventions designed to reduce STF's (e.g., changes to station design, increased provision of assistance services for passengers).

We approached the problem of STF's amongst older passengers by using a systems approach (figure 1), whereby factors related to the individual passenger (e.g., their behaviour, state of health) were considered alongside organisational (e.g., safety policies) and environmental concerns (e.g., weather). The advantage of adopting a systems approach is that it facilitates a consideration of a wide range of factors which are likely to influence STF's, whilst at the same avoiding the problem of focusing too much on specific, idiosyncratic factors in isolation (e.g., station design, passengers behaviour). The systems approach is arguably the dominant paradigm in accident analysis and human factors research. It views socio-technical system accidents as the result of unexpected, uncontrolled relationship between a system's constituent parts. This requires the study of systems as whole entities, rather than considering their parts in isolation [7].

\section{Study phases and methods}

The research took place during the period October 2013 to June 2014 and involved three main data collection phases.

\subsection{Phase 1: Stakeholder interviews and station observations}

A set of 26 semi-structured interviews were carried out with experts involved in safety and risk within the UK rail industry and employed by various bodies including Network Rail, the Rail Safety and Standards Board, as well as the train operating companies. The aim of these interviews was to construct a list of causal factors contributing to STF's and to gather details of how these factors contributed to STF's. A total of 11 stations were observed during the research incorporating a number of station types across the network. During the observations one of the researchers accompanied a member of the station staff and 
asked them about their experiences of passengers STF's, as well as taking photographs and noting down various features of the stations which were relevant to attempts to reduce STF's (e.g., signage, floor surfacing, design of escalators and lifts).

\subsection{Phase 2: Survey of station managers}

A total of 66 station managers completed an on-line survey, covering each of the staffed (but not unstaffed) station types described by Network Rail. The sample represents approximately $10 \%$ of the total number of station managers employed on the rail network. Survey participants were asked a series of questions in the form of 'How important is [factor - e.g., alcohol, station flooring]' in contributing to passenger slips, trips and falls at rail stations (at the current time)'? The same question was posed covering the importance of the issue in the future (2035-2050). Responses were given to each question using a five point scale ( $1=$ Not at all important through to $5=$ Very Important). Participants were drawn from a wide range of locations from stations across Great Britain. Station managers had worked on average for 11.5 years within the rail industry (range 1-36 years) and were employed at National Hub (35\%), Regional Hub (26\%), and Important Feeder (23\%) stations.

\subsection{Phase 3: Interviews with older passengers}

A set of 18 semi-structured interviews were carried out with older passengers. During the interviews participants were asked about their experience of rail travel and the facilities available at train stations which were designed to help them to travel safely and in comfort (e.g., station assistance services, seating areas, escalators, and lifts). The interviewees ranged in age from 67-94 (10 females, 8 males) and were drawn mainly from the personal contacts of the researchers, as well as passengers recruited at local train stations in the East Midlands.

\section{Findings}

\subsection{Factors contributing to older passengers STF's at train stations}

The interviews with stakeholders from rail and other industries, alongside data from observations resulted in a set of 22 organisational, station environment and passenger factors which contribute towards the incidence of STF's at train stations (Table 1). These factors ranged from aspects of passenger behaviour (e.g., rushing carrying baggage, use of alcohol), the state of health of passengers (mental and physical) the design of stations (e.g., signage, escalators, flooring), communication of safety information, provision of assistance service, as well as other factors which may lead to STF's (e.g., crowding). In what 
follows, we summarise the findings as they relate to a selection of the factors (further details are available in [8]).

\subsubsection{Organisational influences - Accident reporting}

The reporting of accidents was an issue that appeared to require attention, with a number of interviewees suggesting that there is not enough time for staff to report and complete accident reports fully and accurately for all accidents and near misses. Accident data was described as incomplete, relying on the trust of staff to record all available information. As a result, accidents and near misses were often underreported unless the accident required medical treatment in which case, a full report is required. Should a STF incident require an ambulance, then the report for the accident is likely to be more comprehensive, due to the severity of the injuries. Some interviewees also stated that although from the data it appears that older passengers experience more STFs than other passengers and frequent commuters, this could be due to underreporting and a reduction in the consequential factors for younger compared to older passengers. Older passengers may sustain greater injuries requiring medical treatment, in which case an ambulance will be called and the accident report is completed. However, our data also suggested that older passengers are less likely to report accidents because of the fear of being stigmatised. The reporting of accidents also appears to depend on the previous experience of station managers and other staff members.

\begin{tabular}{l|l}
\hline Level & Contributory factors to STF's \\
\hline Organisational influences & - Staff training/awareness \\
& $\bullet$ Accountabilities \\
& $\bullet$ Safety culture/campaign \\
& $\bullet$ Safety policies \\
& $\bullet$ Coarning from Accident reporting \\
\hline Station Environment influences & $\bullet$ Extreme weather \\
& $\bullet$ Crowding \\
& $\bullet \quad$ Building regulations \\
& $\bullet \quad$ Seneral station design \\
& $\bullet \quad$ Lift safety \\
& $\bullet \quad$ Escalator safety \\
& $\bullet \quad$ Assistance service \\
\hline Passenger (individual) influences & $\bullet \quad$ Cleaning \& Housekeeping \\
\hline
\end{tabular}




\begin{tabular}{l|l}
\hline Level & Contributory factors to STF's \\
\hline & $\bullet \quad$ Recklessness \\
& $\bullet \quad$ Visual/audio distractions from use of technology \\
& $-\quad$ Footwear \\
& $-\quad$ Frail physical \& mental health \\
& $\bullet \quad$ Rushing / running for the train \\
\hline
\end{tabular}

Table 1. Contributory factors leading to older passenger STF's at train stations

\subsubsection{Organisational influences - Safety and training campaigns}

A number of safety and training campaigns were observed during the station observations and were discussed during the interviews, these included: alcohol bans (Merseyrail, East Midlands Trains); floor cleaning monitoring (Merseyrail); signage designed to reduce STF’s when carrying luggage; staff seminars covering risks associated with the use of escalators; and, other types of advertisements which aim to minimise the risk of STF's occurring.

Floor signage also highlighted the dangers of STFs in stations (Figure 2 shows examples of floor signage at Paddington station). A number of Network Rail advertisements, including a video played on screens in stations and also available on YouTube, were also observed during the station walkarounds. The aim of the advertisements is to draw the commuters' attention to the dangers of improper escalator usage. 

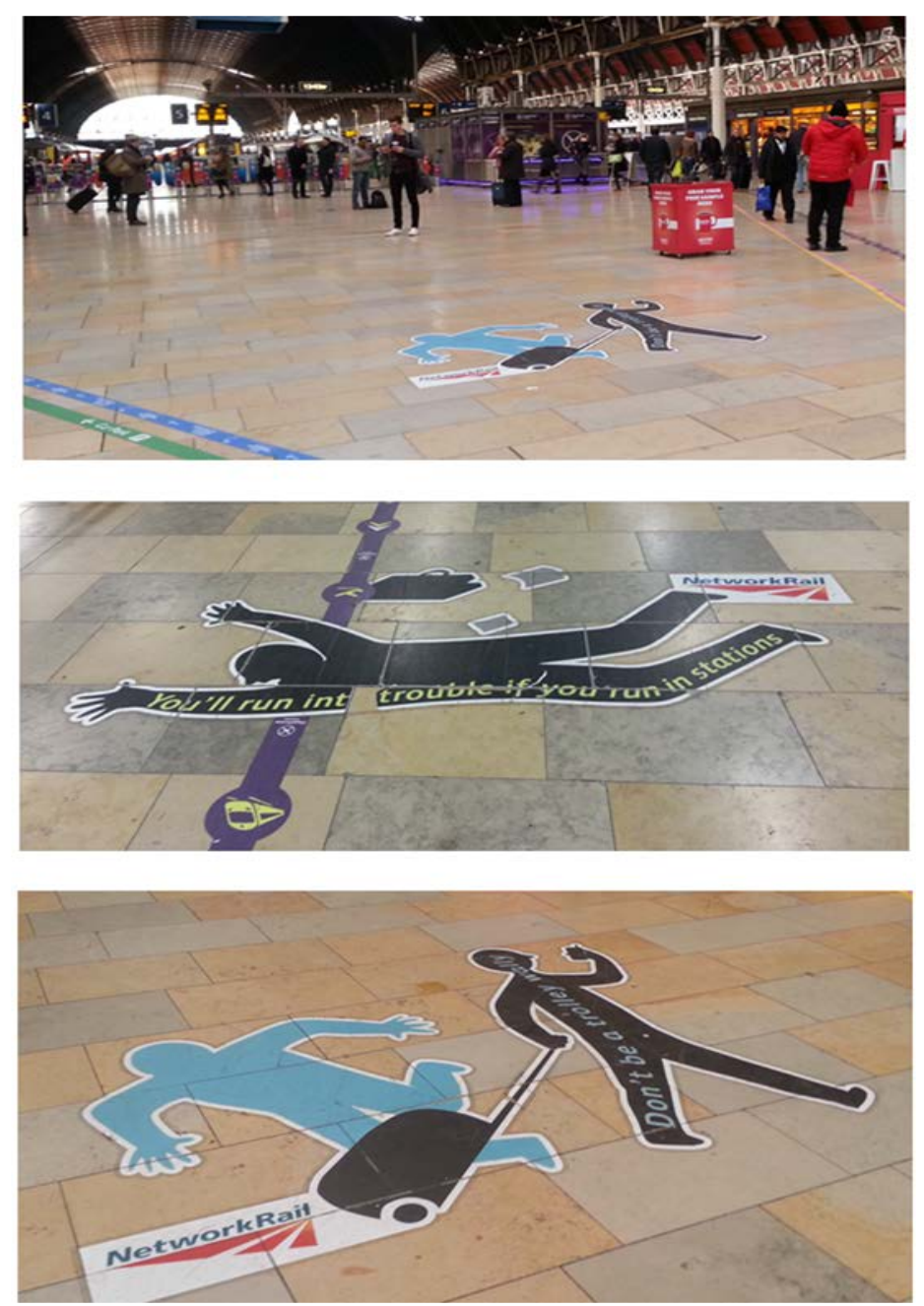

Fig. 2. Floor signage (Paddington Station)

\subsubsection{Organisational influences - Accountabilities}

Accident reporting and identifying areas with high STFs that require improvement can be difficult due in part to the ownership of different areas of a station and the area surrounding it. This sometimes leads to discrepancies in terms of accountabilities and libaility between those responsible for the area on which the accident occurred and other parties (e.g., Network Rail). Some stations are also managed by different Train Operation Companies (TOCs) and this sometimes this differs according to the specific section of the station (e.g., station platform as compared to concourses). For example Liverpool Lime Street station is managed in part by Network Rail and in part by Merseyrail. When an accident occurred in one area of the station it would be reported to Network Rail, whilst in another area, Merseyrail would record the accident data and deal with the issue. Problems with accountability sometimes lead to disputes about who is responsible for putting measures in place to reduce the risks of STF hazards: 
"The area outside of the station is the responsibility of the local authority... we grit the pathways leading to the station... but were told to stop. Then the local authority failed to grit the paths, and passengers started to fall over on their way to the station. The accidents were not being reported to the local authority, and so when we phoned to tell them about the problem, they said that there was no problem, as no accidents had been reported to them...” (Safety Business Advisor)

\subsubsection{Station environment influences - Escalator safety}

The risk associated with escalators were mentioned several times during our interviews and a number of interventions had been put in place at stations order to reduce STF's, these included: the use of barriers to deter passengers from carrying luggage on escalators; encouraging passengers to use the lifts or stairs instead of the escalators; floor signs directing passengers to the nearest lifts; reducing the speed of the escalators. Signage was used to highlight the use of lifts, particularly when carrying luggage (Figure 3), however signage was not always obvious. For example, barriers were used to deter passengers from taking luggage onto the escalators (at Paddington station), however, the signage used was small and not highly visible to oncoming passengers. By contrast signage at Birmingham New Street, appeared to be highly visible, clear and effective in directing passengers to the nearest lifts. During station observations large, clear signage was seen, including large, visible, yellow and black signs placed on the approach to the escalators.
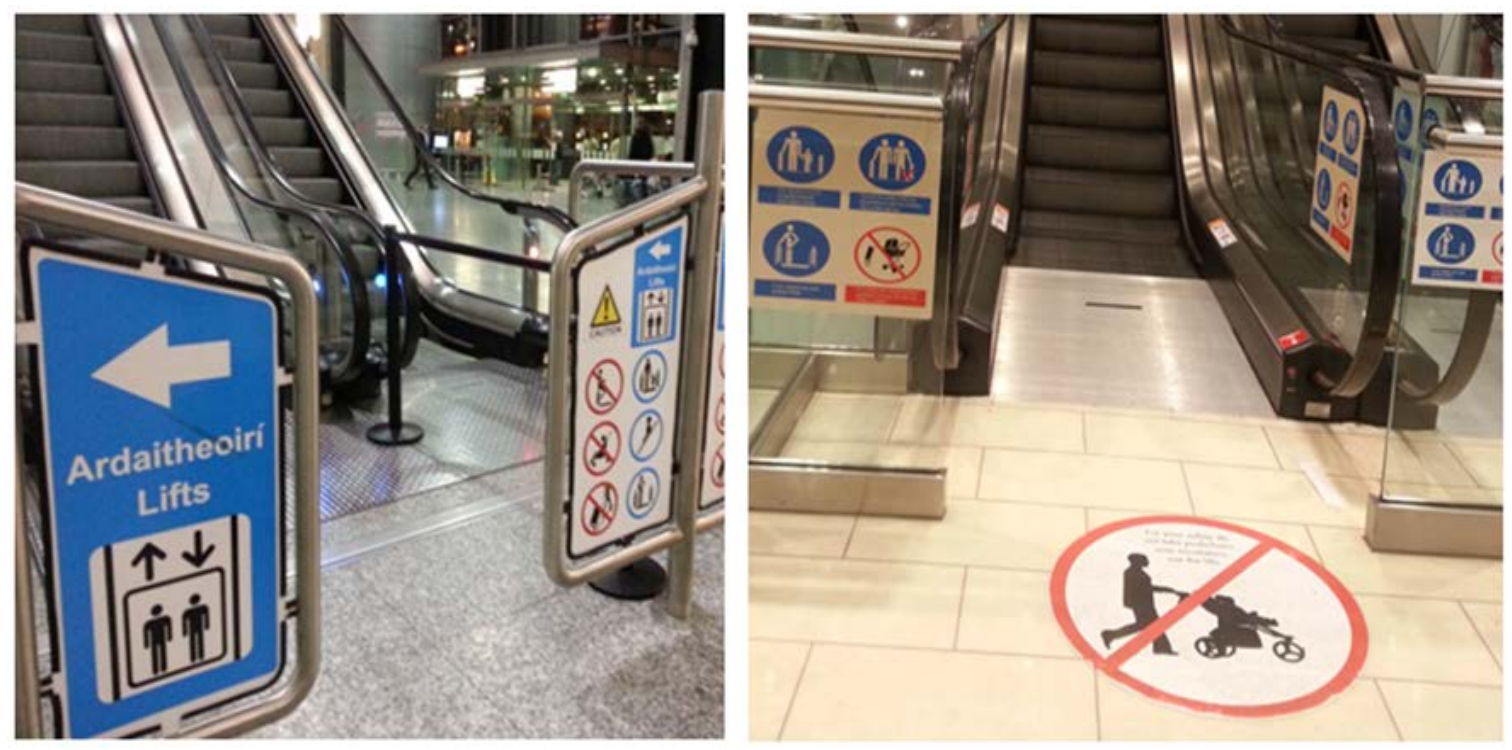

Fig. 3. Examples of escalator signage 


\subsubsection{Station environment influences - Assistance services}

The assistance services offered to vulnerable passengers differed across the rail network. Public announcements are in existence across the network, as well as advertising that assistance is available at stations (e.g., public address announcements such as "Do not struggle on the stairs today, assistance is available at this station...”). The general opinion was that a very good service is provided to passengers, however, it was also pointed out that some passengers abuse the service and though the assistance service is "not a porter service" (Station Manager), some passengers wrongly try to use it as such.

The service is sometimes very busy and may require additional staff to maintain the quality of the service in the future. All the older passengers interviewed were aware of the assistance service available when travelling by train, of which 6 out of the 18 had used the service in the past. All of those described the service as being “reliable...” and "reassuring...”. However, the key issue identified with the assistance service was its availability. At a number of larger stations, passenger assistance vehicles were used to transport wheelchair users and other vulnerable passengers to the platform, similar to that seen at airports. Also, at the entrance to station, and at taxi ranks, and at the platform 'Help point' and assistance buttons are available for passengers to request assistance as and when required. Help points at taxi ranks for example, enable passengers to call for assistance as soon as they arrive at the station. However at a number of stations different policies were in place for station staff to enquire if passengers require assistance at the station. Some stations employed a proactive approach during which staffs were encouraged to identify and assist passengers who require assistance but may not have previously used the service. At other stations, this was felt to be discriminatory and staff were instructed never to offer passengers assistance unless it was directly requested.

\subsubsection{Station environment influences - Impact of extreme weather}

Fluctuations in weather con conditions was an issue highlighted throughout the research which some respondents felt contributes to STFs at stations (including stakeholder interviews, station observations, older passenger interviews, and station managers’ surveys). Issues surrounding snow, ice, rain and leaking roves, as well as wet and slippery flooring (at doorways in particular), and uncovered platforms were some of the examples cited. Stakeholder interviews suggested that leaking roofs caused rainwater to spill onto the platform and this can cause the flooring to get slippery when wet. Some stations use different methods to reduce slippage at stations, including laying moisture absorbing mats. 
"The roof is being repaired... however it still leaks at this end of the station... so when it rains we roll out a large mat and that soaks up the water and stops passengers slipping on the platform. However the mat doesn't sit flat at the ends and so it sort of creates a trip hazard at the same time...” (Station manager)

At Southport station, the safety managers were seen monitoring and carrying out inspections in order to identify areas requiring maintenance and to further ensure that the platforms were all completely covered thus preventing STF's during incremental weather conditions. Additionally, at Liverpool Lime Street station, absorbent mats were used in the entrance of the doorways to absorb water during incremental weather in order to reduce STF's. At Paddington, the roof was being refurbished as the researcher was told that half of the roofing needed repairing before the end of the summer period. The station manager described how slippery the flooring can get when the roof leaks, with large rubber flooring rolled out to absorb the water, again, to try and avoid STF's.

\subsubsection{Passenger (Individual) influences - Rushing}

A number of issues contribute to passengers rushing when they get to the train station, and although rushing is not something that stations can necessarily prevent, measures can be focused on the design of station and the platforms, reducing the time pressures on passengers to catch a train. The financial implications of missing a train also encourage passengers to rush. Encouraging passengers to arrive at the station a number of minutes before their departure time could help to reduce the rushing on platforms.

Issues surrounding the design and layout of the station were discussed. One stakeholder discussed the impact of altering the layout of the station to avoid passengers from viewing approaching trains as they walked towards the platform:

"With the previous design of the station you could see the train coming towards the platform as you walked down the stairs to the platform... this used to make people rush and run down the stairs to catch the train, as they know they were close to missing it. But as soon as the window was covered up, it meant that passengers could no longer see the platform as they approached the platform... and that really reduced the number of STFs at that station...” (Rail Expert, Age Action Alliance)

\subsubsection{Passenger (Individual) influences - Recklessness}

Antisocial behaviour and recklessness, alcohol and drug use at train stations can contribute to the onset of STF's. Interviewees highlighted that a number of older passengers STF's were due in part to 
alcohol consumption. Stakeholders stressed a growing concern for alcohol consumption among the over 65 years age group. Speaking about rail passengers in general one station manager commented:

"Alcohol is major factor in accidents and incidents, as is the general public's lack of awareness of the dangers of doing stupid anti-social things in public areas and on potentially lethal things...”

\subsubsection{Passenger (Individual) influences - Lifestyle, physical and mental health}

The physical health of passengers is an issue that can contribute to STFs in train stations, including: age, hearing, vision, medication, frailty, and fatigue, as well as additional requirements for passengers with disabilities. It was highlighted during stakeholder interviews that the main focus in the past has been upon establishing wheelchair access across stations. The focus on accessibility for wheelchair users is extremely important and is required by law; however grouping health issues together is not always helpful. Other disabilities can be overlooked as a result of focused attention dominating wheelchair users, and often neglecting the requirements of other passengers with special requirements. This focus of attention has often come at the expense of other heath and ability issues that may also influence STFs for older passengers.

"Elderly passengers are so independent they do not realise they are putting their safety at risk especially carrying trollies up and down stairs...” (Station manager)

A number of the interviewees mentioned the need for further training and information in order to educate station staff of the importance of mental health, including depression, and dementia (Alzheimer's disease for example). For example, passengers experiencing mental health problems could be mistaken for being drunk and disorderly, as the symptoms are often very similar to that of someone with Alzheimer's.

\subsection{Current and future priorities: station manager and older passenger points of view}

Table 2 shows ten of the factors which contributed to STF's at stations in order of the ratings of priority based on the responses from survey participants. One of interesting finding to emerge from the data is that station managers view current issues (e.g., alcohol, rushing for trains and aspects of stations design such as flooring) as likely to have similar important in the next few decades. A similar pattern runs through other factors when comparing ratings of their current and future importance. In addition, aspects 
of the general health of passengers, the impact of weather extremes and crowding at stations are seen as of growing importance in the future. The responses to the survey cut across each of the categories (passenger, station and organisational influences) in Table 1 and possibly reflect the view that very little is expected to change in the next few decades. In other words, the priorities will largely remain the same, but may be compounded by environmental factors such as prolonged periods of extreme weather (e.g., the widespread period of heavy rain and flooding in the UK in 2012).

\begin{tabular}{cll}
\hline $\begin{array}{c}\text { Order of } \\
\text { Priority }\end{array}$ & Currently (2014) & 2035-2050 \\
\hline $\mathbf{1}$ & Rushing & Rushing \\
$\mathbf{2}$ & Alcohol & Alcohol \\
$\mathbf{3}$ & Station Flooring & Station Flooring \\
$\mathbf{4}$ & Station Design & Station Design \\
$\mathbf{5}$ & Staff Awareness/Training & Staff Awareness/Training \\
$\mathbf{6}$ & Cleaning and Housekeeping & Assistance Services \\
$\mathbf{7}$ & Lighting & Cleaning and Housekeeping \\
$\mathbf{8}$ & Waiting rooms & Lighting \\
$\mathbf{9}$ & Assistance Services/ Extreme weather & Extreme weather \\
$\mathbf{1 0}$ & Frailty & Way-finding \\
\hline
\end{tabular}

Table 2. Station manager's rating of the importance of factors leading to STF's at stations (currently and in 2035-2050)

The interviews with older passengers, although limited to 18 individuals, pointed to a number of specific factors leading to STF's, some of which were also mentioned by other interviewees and comments made by survey participants. These include:

- Station assistance services: in the majority of cases older passengers praised the quality of assistance they were given at train stations. The station staff were regarded as helpful, supportive and friendly. At the same time some passengers questioned the extent to which other people were aware of the existence of the service and the availability of help at stations;

- Information provision and signage: some older passengers mentioned that in some cases signage and general information about the station was difficult to understand and confusing. This made it difficult to locate, for example, toilet facilities, ticketing machines and offices and exits. Birmingham New Street and St. Pancras International stations were viewed by some older passengers as especially problematic with regard to signage; 
- Escalators and lifts: some passengers were frustrated that lifts were out of order at many of the stations they used. One or two of the interviewees stated that they preferred using lifts to escalators, as the latter were viewed as dangerous and likely to lead them to have a fall.

- Station flooring and housekeeping: passengers mentioned that they had comes across wet platforms during their journeys and this had made them anxious about boarding/alighting from the train. One passenger described having a fall which they attributed to a stations floor which was wet.

Table 3 shows a longer list of contributory factors combined with data from the interviews with older passengers. The factors are described in terms of current and future priorities (high and medium) and include the views of older passengers.

\section{Discussion and future research}

Our research has highlighted the fact that efforts to reduce the number of passengers STF's remain a priority within the rail industry. A glance through recent statistics and accounts of safety performance (e.g., 2014 - [9]) show that every year accidents involving STF's occur at train stations. Many of these accidents involve some of the 22 factors we describe in this paper and many of them involve older passengers. Incident reports frequently mention rushing for a train, the influence of alcohol on behaviour at stations, accidents on escalators etc. What they rarely mention are factors such as the role played by staff training, procedures for accident reporting and the influence of safety campaigns. Predictions concerning the future will always be problematic and although many developments can be anticipated with a degree of certainty (e.g., an older passenger population), many others remain harder to define and quantify (e.g., the impact of climate change). The approach we have taken emphasises that factors which contribute to STF's should not be seen in isolation. As some of our data indicates, aspects of passenger behaviour such as recklessness and rushing may be related to station design. Likewise, individual factors such as passenger physical and mental health, in combination with environmental factors (e.g., weather) may well play a role in contributing to accidents. One avenue for further research is to provide a better understanding of the relationship and causal linkages between the 22 factors in this paper ([10]).

Our research has also shown that several other areas of investigation could be undertaken in the future. Many of these could be implemented at train stations, as well as inputting a wider strategy for reducing STF's across the network, these include:

- Sharing good practice regarding interventions for reducing STF's: during the course of our research we encountered many examples of what might be termed 'good practice' with regard to ideas and 
initiatives designed to reduce STF's. These included material which was used to train stations staff (e.g., guidance on how to recognise when older passengers needed assistance). Although there are opportunities for sharing new ideas and practices within the rail industry (e.g., RSSB's Community Safety Forum, [11]), we were also aware that much more could be done to support knowledge sharing within the industry;

- Accident and incident reporting: data covering accidents at train stations is problematic for a number of reasons. Much of the information that is available from incident reports and databases (e.g., Safety Management Information System - SMIS) is incomplete and it is difficult to build up a picture of the circumstances, precursors and outcomes of passenger STF's. We often found that that once station staff have completed the accident report, and submitted the information, data was sometimes reduced to one causal factor when inputted into SMIS. There is some evidence that new wireless technologies (e.g., tablets, smartphones) are being used for real-time incident reporting. One station manager described software which was used to map accident data onto the station layout, showing the specific location of accidents that occurred. This information is to create a pattern of 'hotspot' areas where STFs occur, and helps to identify where to target interventions at the station. Technology of this kind might help to overcome the barriers (e.g., the amount of time and effort that is needed to report accidents) which exist when reporting incidents/accidents. There are also possibilities of integrating other data (e.g., photographs, weather details, passenger medical records) within these types of systems [12];

- The development of taxonomies to support accident reporting: the systems model described in Table 1 and 3 might form the basis for an improved taxonomy for recording accidents and incidents. A sample of the 22 factors could be used to design a pro forma or checklist (paper-based or electronic) which station managers could complete. In tandem with new technologies (see above), accident reporting might also make use of voice recognition to complete incident reports using elements of the taxonomy as keywords. We note that improved taxonomies for accident reporting are being introduced with some degree of success in a range of other industries where accident occur (e.g., outdoor activities, [13]);

- Risk modelling: A number of techniques for risk modelling are in use within the rail industry. One of the most recent has been the use of Bayesian networks to assess the probability that current risks (e.g., STF's) may increase as a result of increases in the number of passengers at stations (e.g., crowding),a s well as climate change (e.g., flooding). The approach we have described in this paper which makes use of systems model (Table 1 and 3) could be integrated with these types of techniques. Links and causal relationships between the 22 factors could be established, either on the basis of real or simulated data. 
This information could then be probabilistically modelled using Bayesian nets. This type of work is very much experimental, but we note that 'hybrid' approaches within accident and risk model are becoming more common within risk management (e.g., [14, 15]).

- Understanding older passenger behaviour: Finally, there is currently limited understanding around how elderly passengers travel through each station across the rail network. This information would be valuable in order to populate more sophisticated, qualitative risk models. To gather data on the behaviours of older passengers would require extensive station observations in order to map the behaviours of older passengers at different types of stations and to gather further qualitative data. Future research could aim to determine the number of older passengers currently using the rail network, in order to gather normalisation data regarding pedestrian use of stairs, escalators and lifts. In order to populate more sophisticated risk models, further data is required to expand the information available and collection of more detailed data on passenger behaviours.

\section{Acknowledgements}

The work described in this report was funded by the Rail Standards and Safety Board (Rail Research Association UK - RRUKA). We would like to thank RSSB for their continued support and advice during the course of the project, as well as the participants in the study who were generous with the time and help they provided us. Thanks also to the two anonymous reviewers for IET Intelligent Transport Systems for their constructive comments on an earlier version of this paper. Further details of the work described in this paper are available in the form of a report published by RSSB: 'How Safe Will Tomorrow's Railway Be? Managing the Risks of Slips, Trips and Falls for the Ageing Rail Passenger Population: 'Future Proofing Risk Models in Rail’.

\section{References}

[1] Rail Safety and Standards Board (RSSB) 'Annual Safety Performance Report' http://www.rssb.co.uk/Library/risk-analysis-and-safety-reporting/2014-07-aspr-2013-14-full-report.pdf, accessed $2^{\text {nd }}$ March 2015.

[2] Rail Safety and Standards Board (RSSB), 'The effects of an ageing population on rail travel', Report No. S065, (RSSB, 2008).

[3] EU project 'GOAL (Growing older, staying mobile)' www.goal-project.eu (accessed 20 ${ }^{\text {th }}$ August 2015).

[4] Gillespie, L.D., Robertson, M.C., Gillespie, W.J., Sherrington. C., Gates, S., Clemson, L.M., \& Lamb, S.E. Interventions for preventing falls in older people living in the community (Review), The Cochrane Library, 2012, 9. 
[5] Marks R., Allegrante, J.P. Falls prevention programs for older ambulatory community dwellers: From public health research to health promotion policy. 2004, Soz Praventivmed, 49:171 - 178.

[6] Haslam, R., Stubbs, D.: ‘Understanding and Preventing Falls’ (2008, London: Taylor \& Francis)

[7] RSSB, ‘How Safe Will Tomorrow’s Railway Be? Managing the Risks of Slips, Trips and Falls for the Ageing Rail Passenger Population: ‘Future Proofing’ Risk Models in Rail’ , (RSSB, in press).

[8] Underwood, P. and Waterson, P.E., Systemic accident analysis: examining the gap between research and practice. 2015, Accident Analysis and Prevention, 55, 154-164

[9] ‘GB Rail Safety Performance and Trends for 2014’, http://www.rssb.co.uk/Library/about-rssb/SafetyPerformance-and-Trends-2014.pdf (accessed $2^{\text {nd }}$ March 2015)

[10] Waterson. P.E., Robertson, M.M., Cooke, N.J. Militello, L, Roth, E. and Stanton, N.A, Defining the methodological challenges and opportunities for an effective science of sociotechnical systems and safety. Ergonomics, 2015, 58, 650-8.

[11] ‘Community Safety Forum Steering Group’, http://www.rssb.co.uk/groups-and-committees/rssbboard/safety/system-safety-risk-group/people-on-trains-and-stations-risk-group/community-safety-forum-steeringgroup, last accessed $2^{\text {nd }}$ March, 2015.

[12] RSSB 'Platform train interface strategy http://www.rssb.co.uk/Library/improving-industry-performance/201501-platform-train-interface-strategy.pdf (last accessed 1st September 2015).

[13] 'UPLOADS: An incident reporting and learning system for the outdoor education, recreation and adventure sector in Australia’, http://uploadsproject.org/, last accessed $2^{\text {nd }}$ March 2015

[14] Dulac, N. 'A Framework for Dynamic Safety and Risk Management Modelling in Complex Engineering Systems’. Ph.D. Thesis, MIT Department of Aeronautics and Astronautics. Cambridge, MA, MIT, 2007.

[15] Waterson, P.E., Sociotechnical design of work systems. 2015 In J.R. Wilson and S. Sharples (Eds.), Evaluation of Human Work (4th Edition). Boca Raton: CRC Press. 
Contributory factors to STF's

\begin{tabular}{|c|c|c|c|c|}
\hline \multirow[t]{2}{*}{ Level } & \multicolumn{2}{|c|}{ Current (2014) } & \multicolumn{2}{|c|}{$2035-2050$} \\
\hline & High Priority & Medium Priority & High Priority & Medium Priority \\
\hline $\begin{array}{l}\text { Organisational } \\
\text { influences }\end{array}$ & - Staff training/awareness & & - Staff training/awareness & \\
\hline $\begin{array}{c}\text { Station } \\
\text { Environment } \\
\text { influences }\end{array}$ & $\begin{array}{l}\text { - } \text { Extreme weather } \\
\text { - General station design } \\
\text { including flooring, waiting } \\
\text { rooms, lighting* } \\
\text { - Cleaning \& housekeeping } \\
\text { - Assistance service* }\end{array}$ & $\begin{array}{l}\text { - Crowding* } \\
\text { - Signage (warning \& way- } \\
\text { finding)* } \\
\text { - Lift safety }\end{array}$ & $\begin{array}{l}\text { - } \quad \text { Extreme weather } \\
\text { - } \quad \text { including flooring, waiting } \\
\text { rooms, lighting* } \\
\text { - Signage (warning \& way- } \\
\text { finding)* } \\
\text { - Cleaning \& housekeeping } \\
\text { - Assistance service* }\end{array}$ & $\begin{array}{l}\text { - Crowding* } \\
\text { - Lift safety* } \\
\text { - Escalator safety* }\end{array}$ \\
\hline $\begin{array}{l}\text { Passenger } \\
\text { (individual) } \\
\text { influences }\end{array}$ & $\begin{array}{l}\text { - } \text { Alcohol } \\
\text { - } \text { Frail physical health } \\
\text { - } \text { Rushing / running for the } \\
\text { train } \\
\text { - } \quad \text { Carrying, pushing or } \\
\text { pulling }\end{array}$ & $\begin{array}{l}\text { - } \text { Risk awareness } \\
\text { - } \text { Visual/audio distractions } \\
\text { - } \text { Grom use of technology } \\
\text { - Impaired vision } \\
\text { - } \quad \text { Reduced mobility }\end{array}$ & $\begin{array}{l}\text { - } \text { Alcohol } \\
\text { - Rushing \& running for the } \\
\text { train } \\
\text { - Carrying, pushing or } \\
\text { pulling }\end{array}$ & $\begin{array}{l}\text { - } \text { Risk awareness } \\
\text { - } \text { Visual/audio distractions } \\
\text { - } \text { from use of technology } \\
\text { - } \text { Impeneral health } \\
\text { - } \text { Recklessness } \\
\text { - } \text { Frail physical health }\end{array}$ \\
\hline
\end{tabular}

Table 3 Contributory factors leading to older passenger STF's at train stations 